\title{
A RUÍNA E A FORÇA HISTÓRICO-DESTRUTIVA DOS FRAGMENTOS EM WALTER BENJAMIN
}

Elane Abreu de Oliveira ${ }^{1}$

\section{RESUMO}

O pensamento benjaminiano sobre a história, a alegoria e a obra de arte está enfaticamente conectado à ideia de ruína. Tanto na sua investigação sobre o drama barroco, nas suas teses sobre a história, assim como no seu livro sobre as Passagens de Paris, Walter Benjamin se ocupa da tarefa do alegorista ao trazer significados para o fragmento, o estilhaço, o objeto deslocado do tempo linear. A ruína carrega uma força histórica de conhecimento, ao acolher origens não premeditadas na marcha temporal, ao apontar para aquilo que não foi, mas poderia ter sido. Essa possibilidade de romper com o tempo progressivo e impedir o ritmo da natureza também se expressa no caráter destrutivo, do qual Benjamin destaca o potencial de antecipar-se à catástrofe final pela consciência histórica das ruínas. Neste texto, nossa tarefa é explorar certa força contida no pensamento benjaminiano acerca da ruína e o desafio que ela lança ao alegorista, ao historiador, ao colecionador, assim como ao crítico e ao caráter destrutivo.

Palavras-chave: Ruína. História. Alegoria. Walter Benjamin.

\section{THE RUIN AND THE HISTORICAL-DESTRUCTIVE POWER OF THE FRAGMENTS IN WALTER BENJAMIN}

\begin{abstract}
Benjaminian thought on the history, allegory and the artwork is strongly connected to the concept of ruin. In his investigation of the baroque drama, in his theses on the history as well as in his book on the Passageways of Paris, Walter Benjamin deals with allegorist task of bringing up meanings to the fragment, the chip, the object moved from linear time. The ruin carries a historical power of knowledge in containing unpremeditated origins in temporal progression, pointing towards what was not, but it could have been. This possibility of breaking with the progressive time and preventing the nature rhythm also has expression in the destructive character, of which Benjamin highlights the anticipating potential to the final catastrophe because of the historical consciousness of the ruins. In this paper, our task is to explore certain power contained in Benjaminian thought on the ruin and the challenge issued by it to the allegorist, the historian, the collector, as well as to the critic and the destructive character.
\end{abstract}

Keywords: Ruin. History. Allegory. Walter Benjamin.

\footnotetext{
${ }^{1}$ Mestre em Comunicação pela Universidade Federal de Pernambuco (UFPE) e doutoranda da Escola de Comunicação da Universidade Federal do Rio de Janeiro (ECO-UFRJ). Bolsista FAPERJ. E-mail: elaneabreu@gmail.com.
} 
Há um quadro de Klee que se chama Angelus Novus. Representa um anjo que parece querer afastar-se de algo que ele encara fixamente. Seus olhos estão escancarados, sua boca dilatada, suas asas abertas. O anjo da história deve ter esse aspecto. Seu rosto está dirigido para o passado. Onde nós vemos uma cadeia de acontecimentos, ele vê uma catástrofe única, que acumula incansavelmente ruína sobre ruína e a dispersa a nossos pés. Ele gostaria de deter-se para acordar os mortos e juntar os fragmentos. Mas uma tempestade (...) o impele irresistivelmente para o futuro, ao qual ele vira as costas, enquanto um amontoado de ruínas cresce até o céu. Essa tempestade é chamada de progresso ${ }^{2}$.

Na conhecida passagem acima, a imagem de um anjo em catástrofe nos convida a pensar. Aos nossos pés, há ruínas dispersas, que só o anjo vê. Seu olhar é iconoclasta. O congelamento de sua visão catastrófica dá uma dimensão de como o continuum da história progressiva procura silenciar acontecimentos que fogem à sua cadeia, à sua marcha. A força tempestiva do progresso torna homogêneo o tempo, pois o detém em uma sequencia linear em que as ruínas são ignoradas. É um esforço enxergar o tempo da história como saturado de "origens", possíveis de libertação. Contudo, é tarefa da história (do historiador materialista) libertar esses fragmentos silenciados no passado, pois é no despertar das possibilidades abafadas que se pode mudar o presente e libertar o futuro que o passado não teve. "A história é objeto de uma construção cujo lugar não é o tempo homogêneo e vazio, mas um tempo saturado de 'agoras"'3, como Walter Benjamin ressalta na tese 14 de Sobre o Conceito da História.

Ao pensarmos na dispersão de ruínas, acima citada na tese do anjo da história, tomaremos, a partir daqui, essa configuração como central para compreensão fragmentária do tempo histórico. Benjamin recorre às ruínas em seu caráter alegórico, como presentificação do vivo no morto. Esse aspecto é tratado com ênfase em Origem do Drama Barroco Alemão, em que as ruínas são para o pensamento barroco o que devem ser para o historiador materialista. Em outros textos, as ruínas também trazem esse direcionamento alegórico. Então, antes de tudo, é interessante esclarecer o

\footnotetext{
2 BENJAMIN, Walter. Sobre o Conceito da História. In: Magia, Técnica, Arte e Política: ensaios sobre literatura e história da cultura. Obras Escolhidas, Vol. 1, p.226.

3 Idem, ibidem, p.229.
} 
contexto do drama barroco, para daí explanar o sentido de alegoria e sua implicação para pensarmos a ruína.

O homem barroco está imerso em catástrofes porque sua história natural (história-destino) é esvaziada de "força messiânica". Eliminou-se a transcendência ao preço de se secularizar a religião do século XVII, em que tanto a vida humana quanto a sua salvação foram concebidos profanamente. A imanência passou a cegar a história e, com isso, tornou-a natural, ameaçadora. Assim, a história não tendo intencionalidade messiânica, passa a ser história da natureza, sucessiva, formada por catástrofes que culminarão na "catástrofe final". Nesse sentido, a percepção da história barroca como natureza traz como proposta ideal a política absolutista (na figura do Príncipe) como estabilização profana, imanente, em que a ordem deve ser sempre restaurada e a história se faz naturalizada (terrena, evolutiva). Desse contexto se originou o drama barroco, no qual Benjamin se debruça como alegórico.

"A fisionomia alegórica da natureza-história, posta no palco pelo drama, só está verdadeiramente presente como ruína"4. Se Benjamin volta frequentemente ao aspecto arruinado, dramático do barroco para se expressar, é porque os fragmentos do mundo lhe dizem muito. A palavra escrita, no barroco, tende a expressar-se visualmente, como na alegoria. "Na esfera da intenção alegórica, a imagem é fragmento, ruína. Sua beleza simbólica se evapora (...) o falso brilho de totalidade se extingue" ${ }^{5}$. Símbolo e alegoria, então, distinguem-se ${ }^{6}$. O primeiro carrega uma intenção de totalidade, é arbitrário, tem o caráter de convenção. A segunda é incompleta, despedaçada, dialética, aberta a significações, pois "a ambiguidade, a multiplicidade de sentidos é o traço fundamental da alegoria. A alegoria, o Barroco, se orgulham da riqueza de significações"7.

$\mathrm{Na}$ sua relação com a história e com a natureza, o alegorista é aquele que mata. Mata a totalidade, os episódios contextualizados e os chama a significar fora do contexto. Essa presença da morte consiste na "exposição

\footnotetext{
${ }^{4}$ BENJAMIN, Walter. Origem do Drama Barroco Alemão, pp. 199-200.

5 Idem, ibidem, p.198.

6 Há quem diga que "a alegoria engloba o símbolo, transcendendo-o" (KOTHE, p.35).

7 BENJAMIN. Origem do Drama Barroco Alemão, opus cit., p.199.
} 
barroca, mundana, da história como história mundial do sofrimento, significativa apenas nos episódios de declínio (...) Mas se a natureza desde sempre esteve sujeita à morte, desde sempre ela foi alegórica" ${ }^{8}$. Ao lado da significação, então, está a morte, o sofrimento. Isso acontece porque, para significar um objeto, o alegorista o esvazia, retira seu "brilho", transforma-o em ruína, para daí convertê-la em saber. Então, a morte é tanto o que permite construir a alegoria, como é o que nela é representado. A pretensão de totalidade da história natural se enfraquece assim como a totalidade simbólica. Significando, pois, o alegorista quer salvar a história das leis do destino.

Com base nesses primeiros aspectos, que se dirigem à visão barroca da história, é que cremos melhor elucidar a ruína (ou ruínas) benjaminiana. Ruína e história, em Benjamin, estão intimamente entrelaçadas. Sensorialmente, como ruína, a história se fundiu com o cenário de inevitável declínio. $\mathrm{Na}$ concepção barroca, temos uma valorização evidente dos fragmentos como princípio construtivo. Ruínas e fragmentos criam, constroem alegorias. Nesse gesto de criação, a alegoria é violenta, pois extrai do fluxo da história-destino um fragmento de intemporalidade. A violência carrega um sentido positivo, pois quer redimir pelo conhecimento.

"As alegorias são no reino dos pensamentos o que são as ruínas no reino das coisas (...) O que jaz em ruínas, o fragmento significativo, o estilhaço: essa é a matéria mais nobre da criação barroca"9. A ênfase dessa criação não trata o fragmento, a ruína como "reminiscência antiga". É uma "sensibilidade estilística contemporânea". Daí ser comum às obras literárias do período barroco acumular fragmentos e experimentar combiná-los. Podemos dizer que elas, como Benjamin (e sua escrita assistemática), respiram a mesma intenção estética. A falta de hierarquia, de unificação, faz do princípio construtivo ars inveniendi (arte de inventar), combinação de elementos antigos.

Do estilhaço dotado de significação, extraímos um sentido messiânico dado à criação barroca. Ao arrancar o fragmento de sua morte forçando-o a significar, o alegorista muda o percurso temporal catastrófico, no qual a

\footnotetext{
8 Ibidem, p. 188.

9 Ibidem, p.200.
} 
história-destino se sedimenta. Estaria na raiz de todas as obras significativas essa força de transformação. É isso que, ao entender de Benjamin, faz o drama barroco durar. Desde o início, as obras típicas do barroco estavam destinadas à destruição pela crítica. Morrer era o destino delas. "Seu halo se extinguiu, porque era dos mais grosseiros. O que dura é o estranho detalhe das suas referências alegóricas: um objeto de saber, aninhado em ruínas artificiais, cuidadosamente premeditadas"10. Assim, a beleza que dura nessas obras está na alegoria, que sobreviveu à artificialidade das ruínas como objeto de saber. Saber que dá vida ao morto.

A raiz que liga as obras barrocas à alegoria tem uma inclinação para 0 vivo ainda que sob a máscara do morto. A mortificação dessas obras pela crítica é ponto de partida para o despertar de sua beleza adormecida, de seus estilhaços carregados de história. Afirmando-se como ruína (não mais artificial, mas alegoricamente), a obra pode renascer. "Na estrutura alegórica do drama barroco sempre se destacaram essas ruínas, como elementos formais da obra de arte redimida" ${ }^{11}$. Assim, na redenção, associamos a força alegórica à força redentora também inerente à história, que se trata de trazer à tona o que poderia ter sido e não foi. Mas isso só se faz possível quando o alegorista escapa à história-destino.

Por ser, concomitantemente, "imagem fixa e signo com o poder de fixar", sua utilização fica a cargo do alegorista que a significa e ao mesmo tempo a neutraliza. Essa dupla atividade constrói uma escrita cuja imagem é ruína. Inevitável não comparar essa neutralização ou cristalização alegórica à imobilização messiânica da história, relampejante. O alegórico seria o "agora" atual. É identificada uma correspondência entre alegoria barroca e história barroca, sendo esta última anti-história e não história-destino. Sergio Rouanet assinala que "através da figura da morte, a alegoria se relacionava com a história-destino e, através da significação, com a anti-história” 12.

Em um outro texto, Benjamin apresenta o que chama de caráter destrutivo. Notamos, em suas palavras, algumas ligações com o perfil alegorista. "O caráter destrutivo só conhece um lema: criar espaço; só uma

\footnotetext{
${ }^{10}$ BENJAMIN, Walter. Origem do Drama Barroco Alemão, p.203.

${ }^{11}$ Ibidem, p.204.

12 BENJAMIN, Walter. "Apresentação", in Origem do Drama Barroco Alemão, p.42.
} 
atividade: despejar. Sua necessidade de ar fresco e espaço livre é mais forte que todo ódio"13. Se substituirmos "despejar" por "significar", compreenderemos o mesmo sentido da tarefa alegórica, que é de dar significado ao fragmento morto, preenchendo-o, salvando-o. De maneira análoga, em outra passagem, é destacada no caráter destrutivo a atividade de intervir no ritmo da "natureza" a fim de impedir a "catástrofe final", designada pela ordem do destino. "O caráter destrutivo está sempre trabalhando de ânimo novo. É a natureza que lhe prescreve o ritmo, ao menos indiretamente; pois ele deve se antecipar a ela, senão é ela mesma que vai se encarregar da destruição"14.

Indo mais além,

O caráter destrutivo tem a consciência do homem histórico, cujo sentimento básico é a desconfiança insuperável na marcha das coisas e a disposição com que, a todo momento, toma conhecimento de que tudo pode andar mal. Por isso o caráter destrutivo é a confiança em pessoa. (...) O que existe ele converte em ruínas, não por causa das ruínas, mas por causa do caminho que passa através delas ${ }^{15}$.

Fundir a visão alegórica à do historiador é crucial para Benjamin. Ele reitera a importância dessa fusão na descrição do caráter destrutivo que "converte em ruínas" as coisas do mundo para que, assim, possa ver "caminhos", "significados" dentre elas. No seu sentimento de desconfiança da "marcha das coisas", ele traz para si a possibilidade de "conhecimento" do malogro da história. Não ficando de olhos fechados para esse malogro, as ruínas são, para ele, alegóricas, já que podem ser transformadas, experimentadas de uma nova forma. Vemos assim entrelaçadas três disposições em interromper o curso do mundo: a do historiador, a do alegorista e a do caráter destrutivo. Em todas, de uma forma ou de outra, os fragmentos, os destroços são cruciais para que ocorra essa interrupção na marcha.

A visão alegórica do mundo, de ver a vida a partir da morte traz uma sensibilidade que não se encerra na inversão dos termos. Ela é mais

\footnotetext{
${ }^{13}$ BENJAMIN, Walter. O Caráter Destrutivo. In: Rua de Mão Única. Obras escolhidas. Vol. 2, p.236.

14 Ibidem, p.236.

${ }^{15}$ Ibidem, p.237.
} 
aguçada, em outras palavras, na faculdade de perceber a morte existente na vida. É por isso que, para Benjamin, a obra de arte (mais especificamente tratada em seu estudo do drama barroco) é ruína: ela não apenas indicia o que foi, mas as potencialidades não construídas historicamente, o lamento da felicidade perdida no passado. Ruína enquanto obra é índice, registro de esperança, pois uma vez "mantido o registro, mantém-se a promessa de felicidade, eventualmente realizável. Se realizada, a arte seria, talvez, dispensável, pois a vida mesmo seria 'artística"'16.

Estaria na alegoria (que etimologicamente significa "dizer o outro") o prenúncio da "aura"17, que também tem sua ligação histórica. A obra de arte aurática cristaliza algo distante no tempo e no espaço, e sua destruição se configura com o advento das técnicas de reprodutibilidade. Benjamin coloca que, neste contexto de técnicas reprodutíveis, o homem perde sua ligação com a tradição, aquela que tem correspondência com o original, transmitido de geração em geração. A perda ou destruição da aura seria o corte desse elo distante no qual estava impregnada a força primitiva, a "percepção original". O declínio da aura, assim, foi impulsionado pela paixão das massas modernas em "fazer as coisas ficarem mais próximas" pela sua reprodutibilidade ${ }^{18}$.

Comentando essa quebra com o elo original, Rainer Rochlitz aponta que a aura em Benjamin, niilista, sempre está associada à destruição e ao declínio. Destruir, porém, é desmascarar, desnudar a "falsa aparência", é ser bárbaro. "À medida que a idéia de uma autonomia da arte está ligada, para Benjamin, à aura mágica e religiosa, ela não tem mais razão de ser e apresenta, doravante, um caráter puramente ilusório" ${ }^{19}$. É preciso redimir na ruína toda realidade falsa e ilusória. A obra de arte pode ser ruína, atualizável na pluralidade de significações. Esse papel de escavação da obra cabe a mais uma disposição em descontinuar o curso da história: a do crítico.

\footnotetext{
${ }^{16}$ KOTHE, Flavio. Para Ler Benjamin, p.42.

17 Aura: o "aqui e agora" do original. "Aparição única de uma coisa distante, por mais perto que esteja".

${ }^{18}$ BENJAMIN, Walter. A Obra de Arte na Era de sua Reprodutibilidade Técnica. In: Magia, Técnica, Arte e Política: ensaios sobre literatura e história da cultura. Obras Escolhidas, Vol. 1, p.170.

${ }^{19}$ ROCHLITZ, Rainer. O Desencantamento da Arte, p.219.
} 
Para o crítico da obra de arte, o passado deve ser capturado em função de sua atualidade, de sua plurivocidade. Assim como o passado é aberto para o historiador dialético, deve ser também a obra para o crítico. $O$ caráter autônomo de cada uma não pode ser reduzido ao mero documento sócio-histórico do que houve no passado. Sua autonomia está também em ser ruína (e paralelamente não-ruína) de algo que não houve, de ficções, de concretizações em aberto, de alternativas à realidade. A obra é ruína de "algo não havido", por isso, inconsciente.

Em outro de seus escritos, Benjamin define alguns direcionamentos do crítico, reunidos no que nomeou de A Técnica do Crítico em Treze Teses. A terceira tese diz que o crítico "não tem nada a ver com o intérprete de épocas artísticas passadas" 20 . Ou seja, seu interesse é no resgate do passado da obra que repercute em presentes posteriores e não a interpretação do passado circunscrito na época artística. Criticar é apreender o passado da obra no diálogo com a atualidade do próprio crítico e, nesse diálogo, perceber o "rosto" de uma época que o autor faz presente. Benjamin acrescenta na oitava tese que "a posteridade esquece ou celebra. Só o crítico julga no rosto do autor"21.

A celebração de determinadas obras, movimentos artísticos, em detrimento do esquecimento de outros, demonstra um problema que se dá na relação da história com a arte. O que denominamos de "história da arte" só nos mostra a concretização de períodos em que artistas-autores celebrados se inserem na lógica do tempo linear. Contudo, o crítico, como Benjamin aponta acima, julga a obra na sua inter-relação contemporânea com o artista, seu tempo, seu "rosto". Essa inter-relação se estabelece ao passo que o crítico considera a obra/autor como autônoma, ruína.

$\mathrm{Na}$ visão crítica, o passado precisa ser melhor compreendido pois nele já se aninhava o presente. Aí está a astúcia de sua atividade: atentar para a existência do presente no passado. Essa tarefa está diretamente ligada à ressurreição. Quando lembramos a análise que Benjamin faz da obra de Charles Baudelaire e, até mesmo, do próprio Baudelaire em relação a de

\footnotetext{
${ }^{20}$ BENJAMIN, Walter. A Técnica do Crítico em Treze Teses. In: Rua de Mão Única. Obras escolhidas. Vol. 2, p.32.

${ }^{21}$ Ibidem, p.32.
} 
Constantin Guys (o pintor da vida moderna ${ }^{22}$ ), temos, em ambos, exemplos dessa atuação crítica. Ambos apreendem a fisionomia de uma época nas obras ao mesmo tempo em que elas. É o exercício de ver uma "historiografia inconsciente" nas obras, como coloca Flavio Kothe ${ }^{23}$. É o exame duplo da obra: tanto como fenômeno social, quanto como mônada. Isso implica em "decifrar o pacto fugaz" entre as forças contraditórias da obra (passado e presente) no intuito de capturar, atualizar essas forças como em um sonho.

O estudo da obra "deve ser (...) o mover-se na tensão entre estas duas posições. A 'intemporalidade' da obra de arte, como a 'intemporalidade' do inconsciente, é transtemporalidade" ${ }^{24}$. Assim, cabe ao crítico transpor dimensões temporais, desnudar passados para prever futuros, combinar passado, presente e futuro. Contida nessa relação temporal do crítico, está seu esforço em contrastar utopia e realidade da obra de arte que, em outras palavras, é ver a alegoria presente na ruína. Daí surge a correspondência entre a obra de arte/ruína/alegoria e a história. A obra é ruína alegórica que testemunha o sido e o não-sido da história, uma vez que documenta um passado concretizado e aponta, ao mesmo tempo, para o que poderia ter sido e não foi (o sonho).

Também como ruína alegórica pode ser vista a própria história enquanto detrito da possibilidade concretizada (consciente) e índice do que não se concretizou (inconsciente). A aparência e as ocultações do passado, dessa forma, são decisivas para o trabalho do historiador crítico ou do crítico alegórico. Na dialética de ambas, luta-se contra um passado consumado, incapaz de se fazer ressoar no presente e de antecipar-se ao ritmo da marcha. É possível estar atento ao futuro que já dava seus primeiros acordes anos, séculos atrás. Benjamin viu essa disposição não só em Baudelaire, mas em Balzac.

Balzac soube prever as ruínas da burguesia mercantil em Paris. Reconheceu os monumentos burgueses como frágeis, efêmeros, fadados à destruição antes mesmo que eles desmoronassem. Benjamin cita um fragmento do escritor: "As ruínas da Igreja e da Nobreza, as do Feudalismo,

\footnotetext{
${ }^{22}$ BAUDELAIRE, Charles. Sobre a Modernidade.

${ }^{23}$ KOTHE, Flavio. Para Ler Benjamin.

${ }^{24}$ Idem, ibidem, p.46.
} 
da Idade Média são sublimes e hoje enchem de admiração os vencedores, que ficam surpresos, boquiabertos; mas as da Burguesia serão um ignóbil detrito de cartonagem, de gessos, de coloridos" ${ }^{25}$. Estava ali, no auge do século XIX, o anúncio de seu próprio fim. Passagens, intérieurs, pavilhões de exposição, folhetins, publicidade, mercadorias, panoramas. Indícios de um mundo burguês efêmero como resquícios de um mundo onírico.

A utilização dos elementos do sonho no despertar é o caso exemplar do pensamento dialético. Por isso, o pensamento dialético é o órgão do despertar histórico. Cada época sonha não apenas a próxima, mas ao sonhar, esforça-se em despertar. Traz em si mesma seu próprio fim e o desenvolve - como Hegel já o reconheceu - com astúcia. Com o abalo da economia de mercado, começamos a reconhecer os monumentos da burguesia como ruínas antes mesmo de seu desmoronamento ${ }^{26}$.

Passagens é o alvo desse pensamento dialético, alegórico, crítico. Essa obra é uma imensa coleção de notas e citações em que, Benjamin, num empenho surrealista, agarra-se compulsivamente aos detritos da sociedade. Como colecionador, ele se assemelha ao "trapeiro", que encontra nos dejetos, nos objetos ignorados, o tesouro de sua obra. Ele os resignifica, transforma-os em matéria de seu conhecimento, faz com que contenham uma outra história que a sociedade da época não nos contou. Na coleção, é montada uma nova "totalidade" cujos fragmentos, introduzidos em novo contexto, libertam-se de sua função originária. Revela-se para nós um novo "rosto" de uma época.

Há, nessa intenção do colecionador, o empenho de escrever a história como mônada, em que os "detritos" revelam toda uma época, assim como o microcosmo contém e espelha o macrocosmo. Nas palavras de Benjamin: "colecionadores são fisiognomistas do mundo das coisas"27. Assim, dos autores célebres aos anônimos, a obra-coleção das Passagens reúne, em pé de igualdade, citações dos mais diversos tipos para que o todo comunique a fisionomia das coisas e do tempo. Cada fragmento é selecionado com a atenção de um trapeiro que, não podendo recolher todos os cacos, preocupase com que cada um, eleito, guarde algo do todo.

\footnotetext{
${ }^{25}$ BENJAMIN, Walter. Passagens, p. 126

${ }^{26}$ Idem, ibidem, p.51.

${ }^{27}$ Idem, ibidem, p. 241.
} 
Junto ao colecionador-trapeiro, dessa forma, avizinha-se o historiador e o alegorista, assim como o próprio crítico. Comenta Marcio SelligmannSilva: "O colecionador/historiador/alegorista quer salvar na sua $\operatorname{arca}^{28}(\ldots)$ o máximo possível de ruínas da enchente/tempestade chamada progresso/fascismo"29. Nesse gesto, de salvar as coisas de seu destino ignóbil, o colecionador dá um novo salto no céu da história. Daí entendermos que, para a ruína, ainda há história por ser escrita, uma história inconsciente, a ser revelada. Sob sua máscara mortuária, está o indício de sua redenção, do seu futuro a ser libertado.

Somemos às disposições em deter o curso da história, então, a do crítico e a do colecionador, que fazem das ruínas caminho de conhecimento. Ao interpretar as obras de arte ou ao recolher os cacos no presente, eles rejuvenescem o tempo, destroem a ordem causal. As ruínas desafiam a dimensão espaço-temporal com o caos das lembranças (o sido, o ainda, o não-sido). São vestígios do passado na pele do morto, com possibilidades ainda não consumadas. Olgária Matos assim caracteriza o "instante único" das ruínas:

As ruínas contrariam o devir abstrato do tempo, compensando a sistemática tripartição - antes, durante, depois - pela dinâmica pas encore (ainda não) e jamais plus (nunca mais). (...) Instante único, elas atestam um tempo antes do qual nada foi consumado e depois do qual tudo está perdido ${ }^{30}$.

Encarando essa rotura do tempo, parece-nos fundamental sublinhar a possibilidade histórica anacrônica e saturada de origens sugerida a partir e por meio das ruínas. No empenho do alegorista, do historiador, do colecionador, do crítico, há fagulhas e estilhaços do anjo de Paul Klee citado no início do texto, que, boquiaberto, está entre uma grande catástrofe e o desejo de salvar os fragmentos. Construir, ler o mundo pelos caminhos deixados pelas ruínas é um apelo melancólico e iconoclasta ao qual Benjamin nos direciona.

\footnotetext{
${ }^{28} \mathrm{O}$ autor se refere à "arca construída segundo um modelo judeu". As Passagens seria essa enorme "arca".

${ }^{29}$ SELLIGMANN-SILVA, Marcio. Ler o Livro do Mundo, p.185.

${ }^{30}$ MATOS, Olgária. Vestígios, p. 83.
} 


\section{REFERÊNCIAS}

BAUDELAIRE, Charles. Sobre a Modernidade. São Paulo: Paz e terra, 1996.

BENJAMIN, Walter. A Obra de Arte na Era de sua Reprodutibilidade Técnica. In: Magia e Técnica, Arte e Política. Obras escolhidas. Volume 1. Trad. Sergio Paulo Rouanet. São Paulo: Brasiliense, 1994.

A Técnica do Crítico em Treze Teses. In: Rua de mão única. Obras escolhidas. Volume 2. Trad. Rubens Rodrigues Torres Filho e José Carlos Martins Barbosa. São Paulo: Brasiliense, 1995.

O Caráter Destrutivo. In: Rua de mão única. Obras escolhidas.

Volume 2. Trad. Rubens Rodrigues Torres Filho e José Carlos Martins Barbosa. São Paulo: Brasiliense, 1995.

Origem do drama barroco alemão. Trad. Sergio Paulo Rouanet. São Paulo: Brasiliense, 1984.

Passagens. Trad. Irene Aron. Belo Horizonte: Editora UFMG;

São Paulo: Imprensa oficial, 2007.

Sobre o Conceito da História. In: Magia e Técnica, Arte e Política. Obras escolhidas. Volume 1. Trad. Sergio Paulo Rouanet. São Paulo: Brasiliense, 1994.

KOTHE, Flavio. Para Ler Benjamin. Rio de Janeiro: F.Alves, 1976.

MATOS, Olgária. Vestígios: escritos de filosofia e crítica social. São Paulo: Palas Athena, 1998.

ROCHLITZ, Rainer. O Desencantamento da Arte: a filosofia de Walter Benjamin. São Paulo: Edusc, 2003.

ROUANET, Sergio Paulo. "Apresentação". In: Origem do drama barroco alemão. São Paulo: Brasiliense, 1984.

SELLIGMANN-SILVA, Marcio. Ler o Livro do Mundo. São Paulo: lluminuras, 1999. 